\title{
Procrastination, Perfectionism and Test Anxiety: A Perilous Triad
}

\author{
Jade Carvalho ${ }^{1}$, Vrinda Ruparelia ${ }^{2}$, Tasneem Telwala ${ }^{3}$ \\ ${ }^{1}$ Assistant Professor, ${ }^{2-3}$ TYBA students, Department of Psychology, K.C College, Mumbai. \\ Corresponding author: VrindaRuparelia \\ Email-vrindar3@gmail.com
}

\begin{abstract}
Background: Student life is dotted with undertaking of several tests at different levels. It is only natural for some students to react to the task of preparing for tests by procrastinating till the very last moment or by spending excessive time on mastering perfection. In fact, sometimes striving for perfection can itself lead to procrastination or we actually procrastinate so that we can be perfect. The strength of each of these responses has a profound influence on our test anxiety levels. Thus, this study aimed to examine the relationship between procrastination, perfectionism and test anxiety.

Methods: The sample consisted of 89 participants, all between the age group of 17-19. The Procrastination Scale for student population by Lay to measure procrastination levels, Multidimensional Personality Scale by Hewitt and Flett to measure perfectionism levels and Westside Test Anxiety Scale by Richard Driscoll to measure test anxiety levels have been used for this purpose.

Results: Results revealed a moderate negative correlation between self-oriented perfectionism and procrastination whereas a moderate positive correlation has been found each in the case of socially prescribed perfectionism and procrastination, socially prescribed perfectionism and test anxiety as well as procrastination and test anxiety. All the correlations are statistically significant.

Conclusion:The research has important implications for understanding the necessity of bringing about a change in the current education system and also at institutional and individual levels for tackling the problems of procrastination, perfectionism and test anxiety which are commonly faced by Indian college going adolescents today.
\end{abstract}

Keywords: Test anxiety, procrastination, perfectionism.

(Paper received $-3^{\text {rd }}$ January 2018, Peer review completed $-6^{\text {th }}$ January 2018)

(Accepted $-9^{\text {th }}$ January 2018)

\section{INTRODUCTION}

"The secret of getting ahead is getting started"-Mark Twain

A majority of college students today experience the problem of procrastination. Dr. Samuel Johnson, who wrote the first comprehensive English dictionary, had procrastination defined as "delay" making it synonymous to the concepts of scheduling or prioritizing which isn't necessarily true. For instance, putting off the plan for going on a long drive until the weather forecast for heavy rainfall clears is not procrastination, simply precautionary delay. Thus, it can be said that the best definition of this variable is provided by Oxford English Dictionary which sees it as a postponement, "often with the sense of deferring though indecision, when early action would have been preferable." 
Ferrari states that procrastinators often have a perfectionist feature about how others would assess them. For this reason, there is a causal relationship between perfectionism and academic procrastination.

Many authors indicate that perfectionists and procrastinators have some characteristics in common. Both have high standards and want to approve non-realistic beliefs [1]. In addition, both types of individuals experience the fear of making mistakes [1-2] while exhibiting a tendency of attributing importance to the continuation of perpetual success [1]. Burke \& Yuen, 1983; Onwuegbuzie, 2000 also mention to consider the cause and effect relationship between perfectionist and procrastination, researchers suggest that most people exhibit procrastination since they are perfectionists .

Researchers have found correlations between perfectionism and procrastination, with most often a positive correlation between the social dimension of perfectionism and procrastination, and a negative correlation between procrastination and the self-oriented dimension of perfectionism [1,3-7].

Time and again, it has been observed that college students panic about an upcoming examination. However, several researchers have showed that test anxiety tends to decrease many students' test taking abilities, including their ability to demonstrate knowledge of the subject being tested, resulting in decreased test scores and overall grades. Socially prescribed perfectionism shows positive correlations with total anxiety whereas personal standards perfectionism was related to active coping and inversely related to test anxiety [8].

Highly test anxious students often have poor study skills like the inability to structure their study time, adapt their schedules, and establish sufficient time for studying which can lead to an increase in anxiety $[9,11]$. For example, test anxious students often exhibit avoidance or escape behaviors such as academic [9-11, 12]. In the Indian context students are required to appear for several tests per semester under the current education system that largely aims at testing the memory rather than understanding of various concepts. Under such conditions, information overload is likely to take place thereby causing test anxiety. Most often than not students prefer to put off studying as there are hardly any breathing gaps provided by the system itself for engaging in extracurricular activities that rejuvenate them. Given the parental and societal expectations, the average Indian student has learnt to internalize that being perfect in academics equals to a successful life. Also, very often students attempt 5 papers a week which takes a mental and physical toll on them.

The result is falling scores of students at university level, decreased motivation, strained parent-child relationships, marked rise in substance abuse amongst adolescents, expanding records of juvenile delinquency, unhealthy competition, reduced cooperation, soaring number of drop outs and the increased incidence of suicide. Thus, it would be appropriate to dwell on this connection in greater depth and try to understand it with special emphasis on the Indian student population (specifically, Mumbai collegians) enrolled in various undergraduate courses.

The variables used in study are described below:

Procrastination: Lay defined it as a typically as an irrational tendency to delay tasks that should be completed. Procrastination is believed to be associated with several cognitive, behavioural, and affective correlates and is regarded as a "dysfunction of important human abilities" in routine tasks and critical life tasks.

Perfectionism: a personality construct characterized by striving for flawlessness and setting of excessively high standards for performance, accompanied by tendencies toward overly critical evaluations of one's behaviour [1].

The most widely utilized categorization of perfectionism as developed by Hewitt and Flett divides perfectionists into three subgroups: Self-oriented: they hold exceptionally high standards for themselves and critically evaluate their work based on these unrealistic expectations. Socially-prescribed: they believe others have exceedingly high and impractical expectations of them, which places considerable pressures on them to succeed, because they fear being rejected. Lastly, Other-oriented: They constantly appraise and assess the quality of others' work based on unrealistic expectations. Researchers like Hill, McIntire and Bacharach have showed that self oriented perfectionism appears to be predominantly adaptive while other and socially oriented perfectionism appears to be predominantly maladaptive. 
Test Anxiety: Test anxiety is "the set of phenomenological, psychological, and behavioral responses that accompany concern about possible negative consequences or failure on an exam or similar evaluative situations".

Based on the previous research findings and the purpose of this study, it is hypothesized that,

1. There will be a negative correlation between self oriented perfectionism and procrastination.

2. There will be a positive correlation between socially prescribed perfectionism and procrastination.

3. There will be a positive correlation between socially prescribed perfectionism and test anxiety.

4. There will be a positive correlation between test anxiety and procrastination.

\section{METHODOLOGY}

\section{Participants}

The sample consisted of 89 participants, 59 females and 30 males between the age group of 17-19 years, from different streams such as BA, B.com, BMS, BAF across various colleges in South Mumbai. The convenient sampling method was used where participants were given questionnaires based on accessibility and proximity.

Measures

\section{Perfectionism}

The Multidimensional Perfectionism Scale (MPS) was used to determine participants' perfectionism which is a 45 -item measure with three trait subscales measuring self-oriented perfectionism, other-oriented perfectionism, and socially prescribed perfectionism. Participants are rated on a 7-point scale where 1 equals "strongly disagree" and 7 equals "strongly agree." Studies have demonstrated the stability of the MPS subscales in psychiatric patients and have shown that the MPS subscales have adequate concurrent validity, are not influenced by response biases, and that the items require a Grade 6-7 reading level. The internal consistency of the MPS total score was .87 (An Examination of the Multidimensional Perfectionism Scale with a Sample of Academically Talented Children Wayne D. Parker Heinrich Stumpf)

\section{Procrastination}

The General Procrastination Scale was also used in the current study. Lay developed a 20 item measure of general procrastination scored on a point Likert type scale ranging from 1, extremely uncharacteristic, to 5 , extremely characteristic. The GPS has been found to have adequate reliability in procrastination research studies, $\alpha=.84[13]$.

\section{Test Anxiety}

The Westside Test Anxiety Scale by Richard Driscoll and Westside Psychology was used to determine participants anxiety related to giving tests. The scale is constructed to measure anxiety impairments, with most items asking directly about performance impairment or about worrying, which interferes with concentration. Participants are rated on a 5-point scale where 1 equals "strongly disagree" and 5 equals "strongly agree." The Westside scale has high face validity, in that it includes the highly relevant cognitive and impairment factors but omits the marginally relevant over-arousal factor.

\section{Procedure}

The questionnaire was given to participants throughout Mumbai. Following informed consent, participants were required to complete the three study measures. The time taken by each participant to complete the questionnaire was approximately 20 minutes. After the data was collected, the researcher provided information regarding the objectives of the research, scales and the principle of confidentiality.

\section{RESULTS}

\section{Descriptive Statistics}

As shown in Table 1, 30 and 59 numbers of male and female subjects respectively were selected for the sample $(n=89)$ and means for all variables in terms of gender were reported. 


\section{Perfectionism}

In total, 89 participants responded to the Hewitt and Flett's Multidimensional Perfectionism Questionnaire. As illustrated in Figure 1, the mean score of all participants on the dimension of self oriented perfectionism was 73.64 whereas the mean score of all participants on the dimension of socially prescribed perfectionism was 59.81 .

\section{Procrastination}

In total, 89 participants responded to Lay's Procrastination Questionnaire. The mean score of all participants of the procrastination dimension was 55.81. However further inferential statistics were not computed to identify if the difference was statistically significant.

\section{Test Anxiety}

In total, 89 participants responded to the Westside Test Anxiety Scale. The mean score of all participants of the Test anxiety dimension was 2.78 . Of these $46.07 \%$ of our total sample reported particularly high test anxiety.

\section{Analysis of the Relationship between Perfectionism and Procrastination}

Product Moment Correlation coefficients were computed to examine the relationship between perfectionism and procrastination. Interpretation of the correlation (see Table 2) reveals that, as predicted, there was a negativerelationship between Self-oriented perfectionism and procrastination $(r(89)=0.21, p$ $<0.05$ ). There was positive relationship between socially prescribed perfectionism and procrastination ( $\mathrm{r}$ $(89)=0.24, \mathrm{p}<0.05)$.

\section{Analysis of the Relationship between Perfectionism and Test Anxiety}

Interpretation of the correlation (see Table 2) reveals that, as predicted, there was a positive relationship between socially prescribed procrastinationand Test Anxiety $(\mathrm{r}(89)=0.21, \mathrm{p}<0.05)$.

Analysis of the Relationship between Procrastination and Test Anxiety

Interpretation of the correlation between Procrastination and Test Anxiety (see Table 3) reveals that as predicted, there was a positive and statistically significant relationship between Procrastination and Test Anxiety $(\mathrm{r}(89)=0.33, \mathrm{p}<0.001)$.

Table 1 - Mean scores of males, females and both taken together

\begin{tabular}{|c|c|c|c|c|}
\hline & Procrastination & $\begin{array}{c}\text { Self oriented } \\
\text { Perfectionism }\end{array}$ & $\begin{array}{c}\text { Socially Prescribed } \\
\text { Perfectionism }\end{array}$ & Test Anxiety \\
\hline Males & 39 & 73.1 & 61.23 & 2.66 \\
\hline Females & 55.41 & 73.30 & 59.15 & 2.77 \\
\hline Total & 55.81 & 73.64 & 59.81 & 2.78 \\
\hline
\end{tabular}

Table 2 - Correlation between Procrastination, Perfectionism and Test Anxiety

\begin{tabular}{|c|c|c|}
\hline Variable & Self oriented & Socially Prescribed \\
\hline Procrastination & -0.21 & 0.24 \\
\hline Test Anxiety & -- & 0.21 \\
\hline
\end{tabular}

Table 3 - Correlation between Procrastination and Test Anxiety

\begin{tabular}{|c|c|}
\hline Variable & Procrastination \\
\hline Test Anxiety & 0.33 \\
\hline \multicolumn{2}{|c|}{$\mathrm{p}<0.001$} \\
\hline
\end{tabular}




\section{DISCUSSION}

The results of the present study provide some support for the existence of relationships between procrastination and perfectionism, perfectionism and test anxiety as well as procrastination and test anxiety and the findings reveal relationships in the predicted direction.

For the first hypothesis, which states, 'There will be a negative correlation between self oriented perfectionism and procrastination.' it was found that a negative correlation indeed exist between the two variables. This is consistent with the findings obtained by researchers [3-5]. A possible reason for this could be that since people high on self oriented perfectionism tend to set high personal standards for the achievement of which they are internally motivated and thus tend to procrastinate less. Hence, we can say that self oriented perfectionism to some extent is in fact adaptive.

For the second hypothesis, which states, 'There will be a positive correlation between socially prescribed perfectionism and procrastination.' it was found that a positive correlation indeed exist between the two variables. This is consistent with the findings obtained which revealed that the socially prescribed perfectionism dimension was most closely correlated with both generalized procrastination and academic procrastination, especially among males $[1,3,5,6]$. This can be attributed to the fact that procrastination stems, in part, from the desire to avoid the anticipated social disapproval from individuals who are seen as holding perfectionistic standards for others.

For the third hypothesis, which states, 'There will be a positive correlation between socially prescribed perfectionism and test anxiety' it was found that a positive correlation does exist between the two variables. This is consistent with the findings obtained which revealed that socially prescribed perfectionism shows positive correlations with total test anxiety $[8,12]$. A possible reason for this could be that socially prescribed perfectionism is associated with extrinsic motivation for study and thus leads to higher anxiety during exams. Socially prescribed perfectionism is also associated with evaluative concerns thereby generating a negative affect (feelings of inadequacy, depression) leading to poorer test performance.

For the final hypothesis which states, 'There will be a positive correlation between test anxiety and procrastination' it was found that there is indeed a positive correlation between the two variables. This is consistent with the findings obtained. A possible reason for this could be that highly test anxious students have negative evaluative experiences in the past and lack confidence in their future performance due to this or even irrespective of it. They probably have a faulty way of thinking according to which they believe that the efforts that they put in don't match the outcome that they receive and so they may not prepare until the very last moment when it becomes imperative to study to pass the test and so they experience high anxiety levels then. Another factor could be indecisiveness because of which students may delay preparing for the test ending up feeling inadequate and not up to the mark. Thus, we can say that procrastination is an avoidant coping mechanism or escapist behaviour.

\section{Limitations and Recommendations for Further Research}

The present study was conducted on university students. Similar researches may be carried out among students from other levels of education which may yield further insight into the influence of age on the concerned factors. The sample for the present study focused primarily on students of K.C. College. Further studies can be conducted on a wider sample consisting of students of several Mumbai colleges for more reliable results. A similar investigation may be carried out to understand the impact of personality on the relationship between procrastination, perfectionism and test anxiety. Studies can be carried out to understand how the inter relations between procrastination, perfectionism and test anxiety can affect academic achievement. Since the questionnaire was a self-report measure, there is no way to check whether the participants answered honestly or provided socially desirable answers. A similar investigation may be carried out by giving the questionnaires just prior to exams to get a more accurate result for test anxiety. The present study has used the Multidimensional Perfectionism Scale and seen perfectionism in a more maladaptive light, however recent research like the Frost Multidimensional Perfectionism Scale does look at the adaptive aspect of perfectionism. 


\section{CONCLUSION}

It can be concluded that procrastination and perfectionism, perfectionism and test anxiety and procrastination and test anxiety are closely knit phenomena and are in fact common problems faced by college students. This instigates us to take proactive steps at individual, institutional and organizational levels. It would be of great help to determine the causal factors for each of these variables and work accordingly to de-condition students of the established links between these variables so that their ability to actualize academic and personal potential increases.

\section{REFERENCES}

1. Flett GL, Blankstein KR, Hewitt PL, Koledin S. Components of perfectionism and procrastination in college students. Soc Behav Personality 1992;20(2):85-94.

2. Mor S, Day HI, Flett GL, Hewitt PL. Perfectionism, control, and components of performance anxiety in professional artists. Cogn Ther Res 1995;19(2):207-25.

3. Antony MM, Swinson RP. When perfect isn't good enough: Strategies for coping with perfectionism. New Harbinger Publications; 2009.

4. Steel P. The procrastination equation: How to stop putting things off and start getting stuff done. Random House Canada; 2010.

5. Saddler CD, Buley J. Predictors of academic procrastination in college students. Psychol Rep 1999;84(2):686-8.

6. Wernicke RA. Mediational Test of the Relationships Between Perfectionism and Prostractionism. Unpublished master's thesis, American University, USA. 1999.

7. Seo EH. Self-efficacy as a mediator in the relationship between self-oriented perfectionism and academic procrastination. Soc Behav Personality 2008;36(6):753-64.

8. Weiner BA, Carton JS. Avoidant coping: A mediator of maladaptive perfectionism and test anxiety. Personal Individ Diff 2012;52(5):632-6.

9. Zeidner M. Does test anxiety bias scholastic aptitude test performance by gender and sociocultural group? J Personal Assess 1990;55(1-2):145-60.

10. Çapan BE. Relationship among perfectionism, academic procrastination and life satisfaction of university students. Proc Soc Behav Sci 2010;5:1665-71.

11. Cassady JC, Johnson RE. Cognitive test anxiety and academic performance. Contemp Educ Psychol 2002;27(2):270-95.

12. Stoeber J, Feast AR, Hayward JA. Self-oriented and socially prescribed perfectionism: Differential relationships with intrinsic and extrinsic motivation and test anxiety. Personal Individ Diff 2009;47(5):423-8.

13. Steel P, Ferrari J. Sex, education and procrastination: an epidemiological study of procrastinators' characteristics from a global sample. Eur J Personality 2013;27(1):51-8.

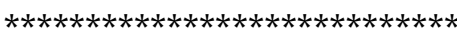

$$
\begin{gathered}
\text { Acknowledgements - Nil } \\
\text { Conflict of Interest - Nil } \\
\text { Funding - Nil }
\end{gathered}
$$

